\title{
Qualitative research as theater: fieldwork in a South African township through the prism of Goffman's dramaturgical metaphor
}

\author{
Caroline Masquillier
}

Department of Sociology, University of Antwerp, Belgium

\begin{abstract}
This autoethnographic paper reflects on the qualitative fieldwork I conducted in a township on the outskirts of Cape Town, South Africa. By exploring how a metaphor can assist in autoethnographic reflection, I aim to gain insight into how data can best be collected in deprived informal settlements characterized by high crime rates. This autoethnographic paper draws on the autobiographical materials of the researcher as primary data. This self-reflexive route, which relied on Erving Goffman's dramaturgical metaphor, helped me to process my various fieldwork experiences in a more systematic manner. Attempting to reconcile my 'work' role - a professional, reliable and confidential advisor - with my 'non-work' role - my supposed real self-involved emotion management and the tools of the stage outlined by Goffman in order that the fieldwork could be conducted in an atmosphere of trust while maintaining a professional distance.
\end{abstract}

Key words: autoethnography, metaphor, role, social interaction, Erving Goffman, participant observation, indepth interview, South Africa

\section{Introduction}

When stimulating a sociological vision, "the more acute people's social marginality, the more likely they are to be keenly aware of their surroundings and to embrace the sociological perspective" (Macionis \& Plummer, 2005: p. 8). As a white, European, middle-class ${ }^{\mathrm{I}}$ female sociological researcher interviewing black people living with $\mathrm{HIV} /$ AIDS (PLWHA) and community health workers (CHWs) in a deprived informal settlement characterized by high crime rates on the outskirts of Cape Town, South Africa, I am stepping out of my familiar routines and becoming the person "on the margins" (Macionis \& Plummer, 2005: p. 8). In the words of Otter, writing about his stay in a neighboring black township, "I'd never before been so conscious of my colour" (Otter, 2007: p. I7). It is not only my white skin, but also my age, class and education - which shapes consider myself to be middle-class, it has been argued that for those living in reduced circumstances such as we encounter here, my status would be seen as considerably higher" (Larkan, 20II: p. 49)". 
how I speak and what I value and believe (Ellis, Adams, \& Bochner, 20I0) - that contrast with those of my respondents.

At the beginning of my fieldwork I unintentionally broke conventional interaction rules in the entirely new setting - such as addressing taboo subject matters without prior knowledge of specific cultural norms related to this. Violating social interaction rules helps to make the means through which reality is constructed explicit (Crawford \& Novak, 2013). As a consequence, a clearer understanding is gained of how people build interactions, how delicate these are and how ingrained the process is. "Fieldwork can be understood as processes where field reports and field analysis are determined by how the researcher interacts with and experiences the field" (Lundgaard Andersen, 20I2: p. I), and it is therefore important that I reflect on these interactions during my fieldwork. To respond to this research need, the first aim of this article is to gain deeper insights into the data collection process, which took place in the deprived informal settlement by writing in an autoethnographic style. Autoethnography is "an approach to research and writing that seeks to describe and systematically analyze (graphy) personal experience (auto) in order to understand cultural experience (ethno)" (Ellis et al., 20Io: p. I). It is both a process and a product (Ellis et al., 2010).

Studying social interaction in everyday life is the focus of micro-sociology (Rafalovich, 2006). One of the leading micro-sociologists of the twentieth century, Erving Goffman (I922-I982), enhanced our understanding of social interaction by using theater as the metaphor for social life (Dexter \& LaMagdeleine, 2002; Goffman, I956; Kivisto \& Pittman, I998; Schulz, 2012). His influential dramaturgical metaphor gave rise to sociological terms which have since become standard in the field, such as social actor and social role, amongst others (Lewis-Beck, Bryman, \& Liao, 2003). As articulated by Dexter and LaMagdeleine (2002), "a metaphor can indicate and predict a researcher's thoughts and perceptions, as well as serve a generative or catalytic purpose" (Dexter \& LaMagdeleine, 2002: p. 362). As a metaphor's goal is to reduce an unfamiliar, complex phenomenon to a more familiar, simpler term (Treviño, 2003), it has the potential to facilitate autoethnography and thus "make personal experience meaningful and cultural experience engaging" (Ellis et al., 20I0: p. 4). In this regard, the second aim of this article is to explore how using a metaphor can assist in autoethnographic reflection. Because Goffman's dramaturgical metaphor depicts social interaction as a grand play, this paper reflects on the participatory observations and in-depth interviews I conducted from my own point of view as the researcher conducting the fieldwork.

\section{The qualitative fieldwork}

This autoethnographic paper draws on the autobiographical materials of the researcher, such as notes made during the fieldwork, the analysis and the writing phase of a qualitative study, as primary data (Boyd, 2008). The fieldwork in this case focused on the interaction between pre-existing social dynamics in the patients' environments and community-based adherence support for PLWHA in South Africa. Ethical approval for the qualitative study was granted by the Ethics Committee at the University of the 
Western Cape ( $13 / 10 / 55)$. Produced as part of a PhD project, the results of this research have been published in various international peer-reviewed scientific journals (Masquillier, Wouters, Mortelmans, \& le Roux Booysen, 2015; Masquillier, Wouters, Mortelmans, \& van Wyk, 20I5; Wouters, Masquillier, Ponnet, \& Booysen, 20I4).

Qualitative research was conducted in collaboration with a local non-governmental organization (NGO) in a township on the outskirts of Cape Town between February and May 20I4. Under the authority of the Western Cape Provincial Department of Health, this NGO trains community health workers (CHWs) in providing adherence support to patients receiving prophylaxis, antiretroviral treatment (ART) and/or tuberculosis (TB) treatment. We asked the CHWs to participate in the study in collaboration with district coordinators from the NGO in question, with the aim of minimizing interruption to service provision. CHWs who agreed to participate took us along on their daily visits to the houses of patients who met the following eligibility criteria: eighteen years or older, HIV positive, and participating in the treatment adherence support program of the NGO in question.

After the observations, patients were given time to reflect on their decision to participate in the in-depth interview. During this time, nine patients cancelled the interview. Of these nine, three were no longer willing to participate in the interview, four were not at home on the date of the interview and could not be traced, and two were unable to attend because of work. These patients might also have been typical of the group that is most difficult to reach in the treatment adherence support program. To prevent the inadvertent disclosure of study participants' HIV status, and to make them as comfortable as possible, participants were permitted to choose the time and place of the interview themselves (Masquillier et al., 20I6).

Respondents completed a short interviewer-administered survey to provide basic socio-demographic information before participating in the semi-structured qualitative interview. Interviews were semi-structured to ensure that the same topics were covered in each, while allowing unanticipated material to emerge. The domains explored through the qualitative interview included HIV testing, disclosure, HIV-related stigma, social support, household involvement and treatment adherence support. Some of the questions in the semi-structured interview related to personal and sensitive issues. The respondent was free to decline to answer any specific question if he or she felt that the information was too sensitive or personal. Furthermore, the principal interviewer and the male and female translators paid specific attention to this aspect and remained sensitive to the limits of the participants.

In order to investigate the interaction between CHWs and their patients' social environments, we collected data not only on the CHWs' and patients' experiences, but also on the interaction between the two parties. In total, four focus group discussions were organized with the $36 \mathrm{CHWs}$, either at the clinic or at the public library; 48 participatory observations were conducted when the CHWs from the NGO visited patients to provide community-based adherence support; and 32 in-depth interviews were held with PLWHA. Of the 32 patients interviewed, ro were male. All patients and CHWs were black 
and all spoke a local language and English as a second/third language. Ten patients had previously defaulted from ART, one of whom was still not taking treatment at the time of the interview. Treatment duration ranged from less than a month to more than 6 years on ART. Most patients were receiving the fixed dose combination. 17 patients reported experiencing side effects from their treatment. $\mathrm{I}_{3}$ of the patients were on both ART and TB treatment. On average, a patient's household numbered four members. I2 patients were not in a relationship, II patients were living with a partner, and 9 were in a relationship but not living with their partner.

During the qualitative part of the study, data was analyzed carefully by reading and rereading the field notes and transcripts of interviews and focus group discussions. The analyses were performed in accordance with the Grounded Theory procedures described by Strauss and Cobin (2008). Following the conceptualization of an HIV/AIDS competent household, a detailed description of which can be found in an article by Masquillier et al. (2015), the analysis focused on how pre-existing dynamics in a patient's social environment interact with community-based treatment adherence programs (Masquillier, Wouters, Mortelmans, Van Wyk, \& Van Damme, In review). It is accepted that, besides 'data triangulation' and 'investigator triangulation', 'respondent validation' also enhances the quality of the data (Mortelmans, 2013). The researcher's understanding of the data collected in this particular social setting was tested against the perceptions of members of that setting, namely the CHWs who participated in the study.

\section{The setting}

The fieldwork has been performed in the Mitchell's Plain/Klipfontein area, which is a densely populated, impoverished urban township area on the periphery of Cape Town, with a population of $65497 \mathrm{I}$, which is predominantly black and colored. This area is confronted with severe social and economic challenges - being one of the poorest areas of the city. Substance abuse, poor schooling and high unemployment are exacerbated by massive population growth (Gilson, Elloker, Olckers, \& Lehmann, 20I4). These social and economic challenges translate in health-related challenges. The township is characterized by an HIV prevalence of $\mathrm{I} 9 . \mathrm{I} \%$; the number of TB cases is also one of the highest in the country, with 26658 cases reported in $201 \mathrm{I}$ (Odendaal \& Lewin, 20I4). Crime and violence, especially murder, rape and drug-related crime, are rampant (Gie, 2009). This township on the outskirts of Cape Town consists predominantly of informal dwellings and the majority of respondents to the interviews had no formal street address.

\section{Goffman's dramaturgical sociology}

William Shakespeare's memorable lines in As You Like It capture the central idea of Goffman's dramaturgical sociology: "All the world's a stage, / And all the men and women merely players; / They have their exists and entrances, / And one man in his time plays many parts" (As You Like It, Act II, Scene VII). The idea of the world being like a stage is the subject of Goffman's PhD thesis, published as his first book with the title The Presentation of Self in Everyday Life. In this micro-sociological work, Goffman investigates social in- 
teraction in terms borrowed from theatrical performance (Jacobsen \& Kristiansen, 20I4; Kivisto \& Pittman, I998; Treviño, 2003).

Goffman's dramaturgical metaphor allows the social scientist to study the day-today social behavior of individuals in public, as though observing actors on stage attempting to convey to an audience a particular impression of the world around them (Kivisto \& Pittman, I998; Schulz, 2012). Introducing the dramaturgical framework, Goffman suggested that when individuals enter the presence of others, they commonly seek to acquire information about them, helping to define the situation and establish expectations about one another (Goffman, I956; Jacobsen \& Kristiansen, 20I4). At the same time, the interlocutors seek to acquire information about the actor, with the same aim of inferring what can be expected of the other in the social interaction (Goffman, I956; Treviño, 2003). To avoid 'creating a scene' - disrupting the social interaction and causing embarrassment one should appear to be who one has claimed to be (Feder-Alford, 2006; Treviño, 2003).

Each individual's performance is described by Goffman as an attempt to form favorable impressions of themselves in the minds of others by conveying information - both consciously and unconsciously (Goffman, 1956; Schulz, 2012). There are many means of conveying the information to others as part of the presentation of the self or impression management (Goffman, 1956; Raffel, 2013). An individual (actor) or group (team) performance for an audience is crafted according to the setting (stage), through scripted dialogues (scripts), social roles (role), tone of voice and gestures (manner), dress (costume) and other objects (props) (Feder-Alford, 2006; Goffman, I956; Kivisto \& Pittman, I998). Together, these aspects can function as a framework for analyzing any form of social interaction, including fieldwork.

\section{Fieldwork through the prism of Goffman's dramaturgical metaphor}

Just as the physical environment of a play on the front stage provides a context and locates the action in a given space and time in the audience's mind, the physical environment creates a context for social interaction. In sociological research, the setting always comes into play (Schulz, 20I2). The patients' homes formed the setting both for the participatory observations performed during treatment adherence support visits from CHWs and for the in-depth interviews with PLWHA. In contrast to theater conditions, I had little control over the 'scenery' for the fieldwork and it therefore differed from home to home.

Elaborating on his dramaturgical metaphor, Goffman considers five key elements: actors, teams and roles; stages; scripts and props; costumes and masks; and audience and outsiders. In what follows, I reflect on the fieldwork within the framework of each of these dramaturgical elements.

Actors, teams and roles

The actors in this fieldwork were the PLWHA, CHWs and one male and one female fieldworker who were there to assist me, the principal investigator. The fieldworkers were selected, like the cast of a performance, by contacting other research institutes operating in the same township. While each actor had an individual role, the fieldworkers 
and myself were seen as a team on stage - as the 'researchers from the university'. Teammates, who are often dissimilar in important aspects, tend to be related to one another by bonds of reciprocal dependence in an interaction in which the relevant definition of the situation is maintained (Goffman, 1956). The fieldworkers used in this study spoke the respondents' local language, lived in a neighboring township and shared a common culture. After every field visit day, I discussed the observations with the fieldworkers. Validity was ensured by having three observers who could cross-check each other's findings in order to discover and eliminate inaccuracies (Angrosino, 2007). Although they were living in neighboring townships, the fieldworkers reported being shocked that fellow South Africans were living in such poor conditions.

A crucial part of Goffman's dramaturgical metaphor is the role (Kivisto \& Pittman, I998): the enactment of rights and responsibilities attached to a given character that an actor is attempting to portray (Goffman, I956; Schulz, 2012). The fieldworkers acted as bridges between myself, the PLWHA and CHWs and were paid for assisting with the interviews and participatory observations. The aim was to make the respondents as comfortable as possible. The fieldworkers assisted in translating not only the questions and answers, but also the ingrained social norms of the local culture to me. Besides performing the treatment adherence support sessions, the role of the CHWs was to guide the research team to the patients' houses during the fieldwork, among the informal dwellings with no formal street addresses. They also assessed whether the research team was welcome and whether the people present were aware of the patient's status, in order to protect the patient's privacy and avoid inadvertently disclosing their HIV status.

To minimize the impact on the treatment adherence support sessions, the research team simply observed rather than participating. They adopted the 'observer-as-participant' role, in which the researcher "is known and recognized, but related to the 'subjects' of study solely as a researcher" (Angrosino, 2007). In this regard, we could compare the researcher's role to the 'stranger', described by Simmel as an outsider who comes today and goes tomorrow (Simmel, I950). For some respondents, the interviews seemed to create a safe space for dialogue, in which I encountered "surprising openness - confidences which sometimes have the character of a confessional and which would be carefully withheld from a more closely related person" (Simmel, I950: p. 2), as this respondent testifies:

"I just share this information with you for the very first time today. I never told anyone about it" (Female PLWHA, 40 years)

However, the stranger is both near and distant at the same time. In Simmel's words (I950): "the stranger is close to us, insofar as we feel between him and ourselves common features of a national, social, occupational, or generally human, nature. He is far from us, insofar as these common features extend beyond him or us, and connect us only because they connect a great many people" (Simmel, I950: p. 2). Between such nearness and distance, "there arises a specific tension when the consciousness that only the quite general is common, stresses what is not common" (Simmel, I950: p. 3). Because of our 
different backgrounds and characteristics, I feared that this distance would be enlarged by my association with the university, which Goffman notes can "foster the impression that the licensed practitioner is someone who has been reconstituted by his learning experience and is now set apart from other men" (Goffman, I956: p.29).

I found that the fear of having a distance between the respondents and myself influenced my impression management. On the one hand, I wanted to project the image of a 'professional' - my 'work role' - and come across as a reliable and confidential advisor who observers objectively and neutrally. Thus, the stranger who is somewhat distant from the respondent. On the other hand, I hoped that the respondents would see me primarily in my 'non-work role', so that they would feel comfortable sharing their stories - the stranger with certain features in common. In this regard, Goffman (1956) explains that each actor "joins with his team-mates in maintaining the appropriate mixture of formality and informality, of distance and intimacy, toward the members of the other team" (Goffman, I956: p. I20). I found it a difficult exercise to maintain the balance between the two roles. The demands of my work role sometimes felt incompatible with the demands of my essential non-work role, "my supposed real sel[f]" (Kivisto \& Pittman, I998: p. 289). These conflicting roles led me to ask myself many questions, such as: How emotionally involved can I become? What should I do in situations of deep distress due to poverty and despair? Where does my neutrality end when it comes to observing what is going on, to understanding the situation? When do I become part of the problem - or part of the solution? It felt to me that my role as a researcher created expectations among some patients that I could help them escape their impoverished situation, that my being there produced a spark of hope.

Depending on the situation, I tried to selectively foreground either my 'work' or 'non-work' role. For instance, despite the fact that respondents were free to decline to answer any question if they felt the information was too sensitive or personal, some questions led respondents to consider aspects of their lives they would not normally think about in great depth. In such situations, I gave priority to my 'non-work' role by being sensitive to the participants' boundaries. While I tried to stay in my 'work' role as a researcher using various tools of the stage, at certain times the lived experience of distress and poverty touched me so deeply that I could no longer simply observe the reality, but also wished to help, for instance by sharing my lunch or handing out extra vouchers for the supermarket, transporting patients too ill to walk to the clinic or offering money for a taxi. At such times, I found myself slipping out of my 'work' role. Goffman (I956) notes: "at moments of great crisis, a new set of motives may suddenly become effective and the established social distance between the teams may sharply increase or decrease, but when the crisis is past, the previous working consensus is likely to be re-established" (Goffman, I956: p. 107).

Attempts to reconcile roles inevitably involve a certain amount of emotion management (Kivisto \& Pittman, I998). However, Kivisto and Pittman (I998) argue that "when this happens, individuals have a wide variety of options, but ultimately none of them is likely to fully resolve the conflict; the best solution in many cases, is to gloss over the 
conflict by acting - by using the tools of the stage" (Kivisto \& Pittman, I998: p.289-290). In what follows, I will discuss how these tools of the stage assisted me in the constant negotiation to maintain the balance between my 'work' and 'non-work' roles.

\section{Stages}

As the necessity of staying in character as 'the researcher' on the front stage can be exhausting (Kivisto \& Pittman, I998), the back stage - my home - provided me with an opportunity to take a break: the back stage is a place where actors address their emotional needs (Kivisto \& Pittman, I998). The actor is allowed to 'be', without having to 'perform' (Schulz, 2012), as "the back region will be the place where the performer can reliably expect that no member of the audience will intrude" (Goffman, I956: p. 70). On this stage "the performer can relax; he can drop his front, forgo speaking his lines, and step out of character" (Goffman, I956: p. 70), while the front stage is the "place where the performance is given" (Goffman, 1956: p. 66). Just as actors have to stay in character, fulfil their roles and develop the favorable impression they wish to create during a performance before an audience (Kivisto \& Pittman, I998; Schulz, 20I2; Treviño, 2003), so too did I feel compelled to control my emotions during the fieldwork. I was especially affected emotionally when a respondent had a similar profile to my own (e.g. female, similar age), as I could more easily imagine myself in her role. I felt, however, that I could not show that I was affected by the respondent's situation - I resisted slipping out of my work role. As Goffman (I956) notes, "it is in the front region that we may expect a tone of formality to prevail” (Goffman, I956: p. 78).

The number of people present during the observations and interviews was determined by the front stage - the size of the house. Depending on the setting, the research team consisting of myself and a fieldworker of the same gender as the patient were joined by other actors. For instance, in a situation in which the female patient was very ill and lying in bed, the male fieldworker waited outside while the female fieldworker and I were joined by the $\mathrm{CHW}$ in order to create a more familiar and comfortable atmosphere. The respondents' homes were often not more than one room, which was itself almost completely occupied by a bed. In this regard, the use of space was also bound by the stage on which I was doing the performance. When a respondent invited me to sit on her bed to interview her, I felt as if I was invading her personal space but it seemed less of an issue for her. The local norms regarding space were much closer than what I was used to. While in my culture a social distance is used for encounters with strangers, during my fieldwork I noticed that the personal distance - reserved in my culture for friends and acquaintances - marked the appropriate distance for meetings between myself and respondents (Griffin, 2006).

The front and back stages coincided with the two sides of Table Mountain, which served as a natural buffer for me between my two worlds: the back stage, where I lived in a more wealthy area among doctors and pharmacists, enclosed by Table Mountain, and the front stage where I conducted the participatory observations and interviews, and where the PLWHAs and CHWs lived, behind the mountain. As a landmark, Table Mountain serves 
as a reminder that both stages, which look and feel so far apart, are actually very close to one another, part of one city. This divide in living spaces has its roots in the I9I3 Natives Land Act, in the 1923 Natives (Urban Areas) Act and in decades of enforced segregation during the apartheid policy. Then, freedom became a reality only for the white minority, who instituted a policy of racial separation with the aim of controlling the black majority (Houssay-Holzschuch \& Teppo, 2009; Kay, 2004; Mahlangeni, 2013; Turok, 200I): "questionable and historically inaccurate racial categories became indisputable realities once they were written on the landscape in the shape of bounded racialized spaces occupied by racialized subjects" (Glen Elder (I997) in Schuermans, 20II: p. I07).

The university, which is also located behind Table Mountain, served the large 'colored'2 population of the Cape Peninsula and beyond during apartheid. Driving to the university and leaving the back stage of my home was like passing through the stage curtain. In dramaturgical analysis, the stage curtain is the permeable boundary between the back stage and the front stage, at which the actor's transition from 'being' to 'performing' takes place (Schulz, 20I2). Goffman notes that "we must keep in mind that when we speak of front and back regions we speak from the reference point of a particular performance, and we speak of the function that the place happens to serve at that time for the given performance" (Goffman, p 77). In this regard, while the township was the front stage on which the fieldwork was conducted, the university also served as a back stage at times - a private place where the actor prepares to go out on stage to perform (Kivisto \& Pittman, I998; Schulz, 20I2). On the back stage, "the team can run through its performance, checking for offending expressions when no one is present to be affronted by them" (Goffman, I956: p. 70). Here, unlike in my home, team members - the fieldworkers assisting me - had access to the preparatory space and we could discuss together what should be changed about the participatory observations and interviews, about the performance (Kivisto \& Pittman, I998). Data collection and analysis phases were alternated to inform subsequent fieldwork and to assess when data saturation had been reached. Furthermore, the university back stage also served as a storage space for physical items that could not be placed on the front stage (Kivisto \& Pittman, 1998), such as the audio-recording material and the completed consent forms and questionnaires. Thus, the data could be stored safely, beyond the reach of anyone not involved in the study and separate from any file that might enable the identification of participants.

\section{Script and props}

Another means of overcoming the tension between my work and non-work roles involved attempting to respect the script. In order to break the ice, I tried to introduce myself to the respondents in the local language, following a vital script: "Molo (Hello), 
Unjani? (How are you?) / Ndiphilile enkosi, unjani wena? (Fine, thank you, how are you?) I Ndiphilile enkosi (Fine, thank you)". The word molo acknowledges the existence of the other person in the interaction, while ndiphilile literally means I am alive. This elaborate greeting, which helps smooth communication, is an "adjacency pair through which most greetings, opening and closings of conversations have an understated rule that as one speaks a line, so another makes the most appropriate conventional response to it" (Macionis \& Plummer, 2005: p. I74).

After entering the respondent's house, the research protocol provided a clear script to follow when doing the field work. The distinct stages of this research protocol can be compared to scenes in a play (Kivisto \& Pittman, I998). For example, if patients agreed to participate in an interview after the observation, a sheet giving more information about the interview would be handed over. Like the information leaflet, this sheet showed my cell phone number along with those of the fieldworkers and a professor with whom I was collaborating. Although respondents seldom made use of this phone number, it could be seen as a bridge between the front stage and my back stage.

Before study enrolment, the purpose of the study, its design and aspects such as voluntariness and confidentiality were explained in an understandable way to the respondents. This information was also provided to them in the form of an information leaflet. Both the information leaflet and consent form were available both in English and the local language. Informed written consent was obtained from all participants in the study with regard to participation, audio recordings and the publication of the findings. The consent form and agreements made beforehand explained the rules for interaction and therefore helped participants in the interaction to define the situation and what they could expect of one another (Goffman, I956). While this was done to protect the respondents' rights, it often felt to me that this consent form stressed my 'work role' too much and did not facilitate a relaxed atmosphere. The consent form also formalized tact, which can be seen as a mutual agreement made between participants "as a way of protecting the performer's performance and 'saving the show'" (Treviño, 2003: p. 36). Agreeing on how to assist in making repairs tactfully if the performance breaks down can help prevent embarrassment (Treviño, 2003), for instance: if there was a question the respondent did not wish to answer, he/she could simply tell the research team so that they could go on to the next question.

It was not possible to prevent embarrassment in all situations, however. For example, when two respondents were asked to sign the consent form, it emerged that they were unable to read or write. In these two instances the information leaflet and consent form became a source of embarrassment for myself. In dramaturgical terms, embarrassment is "the discomfort that follows a spoiled performance. Goffman describes embarrassment simply as losing face" (Macionis \& Plummer, 2005: p. 172). Embarrassment reminds us of the fragility of performances or social interaction. One way I tried to avoid or overcome embarrassment was to refer to the differences between the interaction orders in my home country and South Africa. By making these differences clear, I hoped to anticipate potential violations of the interaction order on my part and to create a more 
relaxed atmosphere by inviting participants to look behind the scenes at my back stage.

The script was determined not only by the consent form and agreements about the rules for the interview, but also by the structure of the questionnaire. Unlike a script for a play, scripted interaction during fieldwork is less formal and not mutual. During the study, the research team used the scripted conversation as a general outline rather than a word-for-word model and the respondents generally remained unaware of it (Kivisto \& Pittman, I998). The interview followed a predictable pattern, although the particulars of the discussion differed between respondents. This was because the interviews were semistructured, in order to ensure that the same topics were covered in each interview while also allowing unanticipated material to emerge. At the end At the end of the interview the roles were reversed, in the sense that I invited the patients to ask us questions or introduce any other topic they would like to discuss. Respondents often asked, for instance, what my motives were for doing the research, or started talking about their religious beliefs.

The script used outside of the patients' houses was less clear to me than the scripted interactions we had during the observations and interviews inside. As a result, I inadvertently asked questions about taboo topics, such as the initiation rituals young men undergo. This question provoked reactions of embarrassment and fear that an outsider might have heard and been offended. Another example was when I wrongly interpreted a group dismantling a recently stolen car as friends helping each other fix this car. As a result of my failure to understand their roles and the associated script, I greeted them in a very relaxed way, which might actually have helped to defuse this potentially dangerous situation.

Because the script is less important in social interaction than it is in theater, other "sign-vehicles" (Goffman, I956: p. I) which can be controlled more closely, such as props, may be used to convey a person's role in a social interaction (Kivisto \& Pittman, 1998). Props are objects that the actor utilizes in order to express his or her role better (Schulz, 20I2). The consent form, information leaflet and audio-recording equipment all supported my work role as a researcher. All interviews except one were audiotaped; this allowed us to produce detailed transcripts, which served as the basis for data analysis and ensured accuracy. One respondent did not allow us to record the interview, because she was afraid the prop would result in the disclosure of her HIV status. She also hid other props associated with the performance, such as the information leaflet and consent form, from outsiders. The information leaflet, consent form and recording device functioned as brackets around the performance of conducting an in-depth interview. I noticed, for example, that I was more likely to slip out of my work role once the recording device had been switched off. Off the record, after the interview, the respondents and I tended to be more relaxed and to speak in more detail about my non-work role. In exchanging anecdotes about my personal life, I foregrounded my non-work role and afforded the participants a glance behind the scenes, which often created a relaxed atmosphere and allowed the respondents to laugh and offer comments of their own (Norrick, 2009).

Respondents who completed the interview received a voucher as a token of our appreciation for their time and cooperation. This voucher and the document they were 
asked to sign to record receipt constituted additional Goffmanesque props which marked the end of the interview. When leaving their houses after the interviews, I gave the patients a hug goodbye in an attempt to adopt the local norms regarding personal space. Through this form of non-verbal communication, I hoped to stress my 'non-work' role and convey my feelings of caring for them. To stress our human similarities further, I also tried to sit lower than the respondent during each interview, on the floor or a little bench, "since using more space conveys a non-verbal message of personal importance" (Macionis \& Plummer, 2005: p. I72).

\section{Costumes and masks}

Kivisto and Pittman point out that "no matter how well an actor understands his or her role, he or she must be capable of conveying it to an audience" (Kivisto \& Pittman, I998: p. 276). One element crucial to actors is their personal front: characteristics that we most intimately identify with the performer, such as gender, age, racial characteristics, size, looks and facial expressions (Goffman, I956). As my personal front differed from those of both my respondents and fieldworkers in various regards, I tried to bridge the gap through clothes - the costume, in dramaturgical terms. An actor's costume consists of the clothes that he or she wears in order to provide cues to other actors and to the audience about his or her role, since clothes are saturated with social meaning and provide clues about the wearer and his or her social status (Goffman, 1956; Kivisto \& Pittman, I998; Schulz, 20I2).

As my white skin could be seen as a sign of wealth, I attempted to avoid further outward displays of wealth through my costume and props, both in an attempt to adapt to the wealth standards of my respondents and also for safety reasons. While I tried not to wear brands or outfits that suggested wealth, I still aimed to communicate a professional work role by wearing respectable, non-provocative clothes. The CHWs and fieldworkers advised me not to wear certain colors associated with particular political parties, as this could have been provocative at the time of the South African general elections - the period during which my fieldwork was conducted. Furthermore, when the fieldworkers became aware of the cues provided by the costumes and props of outsiders, which indicated that they were part of a violent gang operating in the area, they warned me that my safety could be threatened. As a result of the fieldworkers' ability to understand the roles these outsiders were playing, I spent one fieldwork day in the waiting room of the clinic while the fieldworkers conducted interviews in a gang-infested area.

A mask allows an actor to make his or her role clearer to the audience. Goffman also noted, however, that an actor's use of a mask may add an element of inauthenticity (Schulz, 20I2). The respondents in our study are likely to have received clear signals about my 'work' role as a researcher from the university logos on the information leaflet and consent form. When I was feeling too powerless to help a respondent I sometimes hid in some way behind my 'work' role as an objective researcher, much like an actor hides behind a mask. Thus the performer can "suppress his spontaneous feelings in order to give the appearance of sticking to the affective line" (Goffman, I956: p. I38). 
Gestures and use of space supplement spoken words in conveying information to others. By smiling and making eye contact in order to initiate social interaction, I hoped to stress my 'non-work' role. Similarly, by encouraging a 'backstage style', including reciprocal first-naming, I tried to make the front stage situation feel more like a back stage encounter in which respondents felt comfortable enough to share their back stage stories (Goffman, I956: p. 78). Laughing together functioned as an invitation to reduce social distance and formality, and thus facilitated friendly interaction. It also helped to restore the fragile interactions when these were disrupted, for example when the fieldworkers indicated that I had unintentionally broken conventional interaction rules. In Goffman's words (I956): "at such moments the whole dramaturgical structure of social interaction is suddenly and poignantly laid bare, and the line separating the team momentarily disappears. Whether this close view of things brings shame or laughter, the teams are likely to draw rapidly back into their appointed characters" (Goffman, I956: p. I49). Moreover, I hoped that this shared laughter would reduce the power distance and bring us together as participants, leveling the field as it were (Glenn, 2010; Goffman, 1956; Norrick, 2009). However, as I was the one who generally stopped laughing first in order to get back to the interview, it also revealed the roles of interviewer and interviewee and our developing understandings of the constraints and obligations of our roles (Glenn, 2010). In Goffman's (I956) dramaturgical terms: "the performer can show not only that he is not bound by the official interaction but also that he has this interaction so much under control that he can toy with it at will" (Goffman, I956: p. I20).

\section{Audience and outsiders}

While the actors appear on both the front and back stages, the audience - the collective body reacting to the play - only has access to the former (Goffman, I956). It is assumed that the actor does not know anyone in the audience and that the audience have never seen the actor in this role before (Schulz, 2012). The target audience for my research includes readers of the journal articles and any audiences to whom I present the results of the fieldwork, among others. Reactions from the audience provide feedback about whether each actor has succeeded in enacting his or her role (Schulz, 20I2). Similarly, questions or remarks from the audience for my presentation and/or publication give me feedback about my work.

We should also consider individuals who are neither actors nor members of the audience, and who are not present during a performance, but who nevertheless have access to related information. With regard to my study, these individuals are the peer reviewers of scientific journal articles I write, the review board of the ethical committee and my academic supervisors. In Goffman's words, the role of each of these figures is to "check up on the standards that performers maintain [...] as a protective agent for the unsuspecting public, playing the role of audience with more perception and ethical strictness than ordinary observes are likely to employ" (Goffman, I956: p. 9I - 92). While I discussed both the script and the performance with my supervisors, the ethical committee and reviewers are only able to evaluate the script and a report of the performance. In such a report, the qualita- 
tive researcher should describe all aspects of his or her performance in a transparent way (Flick, 2008). Often, reviewers evaluate this performance based on formal criteria, such as the "consolidated criteria for reporting qualitative research" (COREQ), a checklist for the explicit and comprehensive reporting of qualitative studies (Tong, Sainsbury, \& Craig, 2007).

While the audience has access to the front stage via the peer-reviewed report of the performance, outsiders are excluded entirely (Goffman, 1956). In Goffman's (1956) words: "outsiders know neither the secrets of the performance nor the appearance of reality fostered by it" (Goffman, I956: p. 90). When an outsider unexpectedly intrudes on "a performance that was not meant for him, difficult problems in impression management arise" (Goffman, 1956: p. 85). The degree of interaction between outsiders and the research team in our study was influenced by the setting. Where the houses were closer to each other, there was much more interaction with outsiders and much less privacy than in streets with pavements and more space between houses. During the performance, we tried to avoid interacting with outsiders, such as people in the house or community who may have been unaware of the patient's HIV status, for instance by not sitting in the doorway so that outsiders could see us in the patient's house. When outsiders were present, we did not reveal that the research was focused on HIV/AIDS; furthermore, the participatory observations were not performed and interviews were stopped when outsiders came onto the stage. Goffman (I956) explains that "a team must be able to keep its secrets and have its secrets kept [...] because disclosure of different types of secrets can threaten a performance in different ways" (Goffman, 1956: p. 87). The main reasons for keeping this secret were to avoid inadvertently disclosing a PLWHA's status and to protect patients' privacy. The respondents themselves also employed strategies to conceal the true purpose of the visit. As Goffman (1956) notes, "an intrusion may be handled by having those present switch to a definition of the situation into which the intruder can be incorporated" (Goffman, I956: p. 85); thus, the participants often introduced us as people doing research on TB a disease seen as less stigmatizing than HIV. However, it was important which definition of the situation was switched to. One CHW told an outsider that my role was to collect a debt. Given the impoverished setting, characterized by high crime rates, this new definition of the situation did safeguard the patient's status but also threatened my safety. As a consequence, I did not participate in interviews in the same area on the next day.

The importance of the civil inattention rule defined by Goffman became clear when outsiders broke this rule during the study. Normally, people who are in close proximity demonstrate that they are aware of one another by making brief eye contact, showing that they do not suspect each other of malice. Outsiders in the townships stared at me when I walked by, however, as the color of my skin made me stand out in the surroundings. This feeling was in line with those reported by respondents in Scheurmans' (20II) work: "although a lot of people avoided the underprivileged neighbourhoods completely, the people who had visited them said that they had not felt uncomfortable because of the crime threat, but because of the fact that they were the only white, middle class person around there" (Schuermans, 20II: p. 256). Nevertheless, when walking through the township - 
which is generally considered to be unsafe - I tried to look as though I felt comfortable and safe in the area. When I asked my fieldworkers whether my performance was successful on this point, they remarked that my body language in general gave the impression that I was relaxed. But just then, the tense way I was holding my fabric bag, which contained the props for the fieldwork, revealed that the opposite was true. As a result, I paid extra attention to my bag and tried harder to align my non-verbal communication with the impression I wished to convey. Consistent with Goffman theory, I discovered that nonverbal communication is much harder to control than verbal modes of expression (Goffman, I956). Similarly, the non-verbal communication of respondents sometimes said much more than their words. For instance, while talking about the impact that HIV has had on her life, a young woman's eyes filled with tears and she looked away, unable to speak for a while. However, I was not always able to interpret respondents' facial expressions correctly. For example, when one patient asked for more information in the local language, I inferred from her gestures and facial expression that she was very calm. The fieldworkers later told me that she had in fact been very angry.

\section{Discussion}

This paper reflects on the qualitative fieldwork I conducted in a township on the outskirts of Cape Town through the lens of Goffman's dramaturgical metaphor (Goffman, 1956). My aim was twofold: firstly, to gain deeper insights into the data collection, and secondly, to explore how using a metaphor can assist in autoethnographic reflection. With regard to the first aim, this autoethnography taught me that my fieldwork was like a constantly shifting play which evolved based on ad hoc evaluations of the stage. The performance was flexible and varied according to the stage; this affected, for example, which costume would be worn depending on the people being visited and the broader context; which actors could be present depending on the size of the stage and the respondent; whether written or oral informed consent had to be requested depending on the respondent's competence; whether secrets had to be kept and whether the performance had to be stopped depending on the presence of outsiders. Furthermore, the reflection allowed me to develop an understanding of how fieldwork consists of fragile social interactions in which many sources and carriers of information are used for impression management (Goffman, 1956; Raffel, 2013).

For me, reconciling my 'work' and 'non-work' roles was the most difficult aspect of conducting fieldwork in this deprived informal settlement. The tension of this reconciliation recalls Simmel's 'stranger', who is both near and distant at the same time (Simmel, I950). Trying to maintain the balance between such nearness and distance between myself and the respondents influenced my impression management. Similarly, bridging the gap between myself and my respondents - constructed by patterns of language, color and education - involved emotion management and the tools of the stage. On the one hand, I attempted to convey my 'work' role as a professional, reliable and confidential advisor who observes objectively and neutrally. On the other hand, I hoped to foreground my 'non-work' role - "my supposed real sel[f]" (Kivisto \& Pittman, I998: p. 289) - so that 
they would feel comfortable with me. By encouraging a backstage style, including reciprocal first-naming and laughter (Goffman, I956: p. 78), I wished to make the front stage more like a back stage, so that respondents felt comfortable enough to share their back stage stories. However, at certain times the lived experience of distress and poverty affected me so deeply that I could no longer only observe the reality, but felt compelled to slip out of my work role and try to help. In the words of Larkan and van Wyk (20II), discussing research in similar circumstances, "I cannot remain the passive observer in these circumstances. I am forced to engage fully as a fellow human being" (Larkan, 20II: p. 48). At the same time, when feelings of powerlessness were predominant, I was able to hide in some way behind my role as an objective researcher, much like an actor hides behind a mask. Like in drama I tried to engage at an emotional level, while not jettisoning reason.

This autoethnographic reflection also revealed that interactions in the township, outside of the patients' houses, were much more difficult for me. Understanding the impression management of outsiders, their roles, scripts, costumes and props, was a challenge. Because of this, I violated the interaction order more often on this stage than in the patients' houses, for instance by asking questions about taboo topics or misinterpreting criminal behavior. When entering the front stage, the house of the patient, the roles of interviewer and interviewee were much clearer. The research script gave me something to hold on to, as did the props bracketing the interaction.

With regard to the second aim, this article demonstrates the value of using a metaphor as a guide for autoethnographic writing. The metaphor functioned as a catalyst or vehicle for reflection and clarification of the key themes and unexamined patterns in the fieldwork around which this paper centers (Dexter \& LaMagdeleine, 2002). Because I was inevitably so personally involved in writing this autoethnography, whose subject is my own interaction, and because the process entails a high degree of subjectivity and emotionality (Anderson, 2006; Atkinson, 2006; Ellis et al., 2010), the metaphor provided an invaluable framework for developing insights, reflecting and questioning what happened during the fieldwork (Gibbon, 2012). Goffman's metaphor has thus enriched my own emerging understanding of the fieldwork.

Nevertheless, I remained aware that relying on a metaphor could also narrow my thinking. As metaphors can be interpreted in multiple ways, I followed Dexter and LaMagdeleine's advice (2002) to "hold conversations with people of various backgrounds about a conceptual metaphor [which] becomes a good way to quickly generate alternative avenues of thought" (Dexter \& LaMagdeleine, 2002: p. 378). Such conversations showed me the limits of Goffman's dramaturgical metaphor when it came to understanding my fieldwork. They challenged me to push against these limits and think beyond where Goffman had guided me. In his later work, Goffman himself recognized the limitations of his dramaturgical imagery in capturing the entirety of the social experience (Treviño, 2003). While his work is still compelling in its identification of key phenomena, critics have highlighted various flaws in his theory (Raffel, 2013). For example, actors in a play attempt to convey an impression which is not real; my major concern, however, was to remain faithful to "my supposed real sel[f]" (Kivisto \& Pittman, I998: p. 289). This con- 
flicts with Goffman's dramaturgical perspective, which "does not allow him [Goffman] to accept that anyone actually is, in the normal sense of the word, sincere" (Raffel, 2013: p. I70). An in-depth study of micro-sociology and Goffman's legacy is beyond the scope of this article; instead, the metaphor is used as a backdrop against which to frame my reflections. Future autoethnographic work could explore the use of other micro-sociological theories and metaphors for reflecting on fieldwork.

The product, this autoethnographic paper (Ellis et al., 2010), may be of interest for sociology instructors in illustrating the everyday relevance of sociology. Using Goffman's dramaturgical insights as a framework for reflecting on qualitative fieldwork might be beneficial for teaching purposes. This paper can provide an example for students of how to "make meaningful connections between the conceptual subject matter of a sociology course and their own social worlds - 'cultivating a sociological perspective"” (Rafalovich, 2006: p. 156). Not only for sociological classes, but also for methodological courses this article may be useful to reflect on qualitative research in complex contexts - with attention for negotiation of relationships and space; crossing of boundaries; emotional involvement of the researcher; importance of fieldworkers; among other aspects. The subject of this autoethnography was inevitably determined by myself and does not, therefore, encompass the full reality of any given event or experience; it remains within the boundaries of the researcher's own perspective (Boyd, 2008). That said, this paper contributes to the sincerity of the overall $\mathrm{PhD}$ project, which is one of the key markers of quality in qualitative research (Tracy, 2010).

It has been said that an autoethnography often raises "more questions than it answers" (Boyd, 2008: p. 216). First, the article showed that the 'stranger' role created a safe space for dialogue for many respondents. In this regard, the respondents' feedback on the research reflected Nhamo and colleagues' (2010) experience that "the interview setting had provided people with social spaces to talk about their doubts, uncertainties and experiences of HIV/AIDS in their own lives - a rare opportunity" (Nhamo, Campbell, \& Gregson, 2010: p. I665). It helped the respondents to process aspects of their own lives which they had rarely been able to do "through a lack of opportunity to process and discuss information in a safe and sympathetic context" (Nhamo et al., 2010: p. I665). Furthermore, my 'stranger' role also helped me to identify patterns, which might have been too obvious for people living in that context. On the other hand, this autoethnography made me aware of all the disadvantages of being a 'stranger': I did not understand the respondents' local language and was not always able to interpret their non-verbal communication, so I might have missed opportunities to probe further. A second question raised by this reflection is whether it might have been better to visit the patients without the CHWs to encourage more openness. At the same time, the CHWs were needed to find the patients' houses in the jumble of alleys in the informal settlement. Furthermore, they were better placed to assess whether the research team was welcome and whether the people present were aware of the HIV patient's status, in order to avoid inadvertent disclosure and to protect patients' privacy. In certain instances, the presence of the CHW seemed to create a more comfortable interview setting for the patient. Third, I wonder 
now whether it would be possible for me to do the same type of fieldwork again in the future: I might be less naive and more aware of dangerous situations, making it difficult to appear as relaxed as I did. This reflection also made me question my respondents' understanding of my own health status and whether this understanding affected their responses. As explained by Radley and Billig (I996), respondents' narratives can be influenced by the health status of the researcher: "while we are not told about the health status of the investigators, it is likely that they are understood as being 'healthy'. [...] In consequence, respondents with a medical diagnosis are nearly always in the position of speaking to people who are not only seen to be experts in these matters, but are also health-privileged in the interviewing relationship itself, by the very fact that the interview is taking place at all" (Radley \& Billig, 1996: p. 225). Future research should therefore take into account perceptions of the researcher's health status when reflecting on qualitative research that focuses on respondents' health. Another question this autoethnography raised is whether it is my role as a researcher to provide more assistance to people in need than the ad hoc help I provided when confronted with distressing situations. This reflection and my experiences in the field have taught me to have more information on hand about services and institutions that can provide more sustainable support, so that I can inform respondents about the possibilities of securing longer-term help.

Schulz points out that "reflexivity of one's behavior through impression management allows the individual to learn from past behaviors in order to make better decisions in the future" (Schulz, 2012: p. I), and the process of writing this autoethnography (Ellis et al., 2010) has shown me that the qualitative researcher grows and develops continuously in his or her role (Mortelmans, 2013). This autoethnographic reflection taught me that the research process is influenced by how I balance my 'work' and 'non-work' roles and by how successful I am in impression management. I also discovered that there are cultural differences in the art of impression management. In Goffman's dramaturgical terms: "given our general dramaturgical rules and inclinations for conducting action, we must not overlook areas of life in other societies in which other rules are apparently followed" (Goffman, 1956: p. 157). Furthermore, by making me the person "on the margins" (Macionis \& Plummer, 2005: p. 8), the fieldwork caused me to step out of familiar routines and look at my own life and culture with a new awareness and curiosity. It forced me to look at my own culture through a foreign lens and see "the strange in the familiar" (Jubas \& Seidel, 20I4: p. 20). The excitement of seeing familiar meanings transformed (Berger, 1963 ) is nicely described in 'The Body Ritual Among the Nacirema' by Horace Miner (Miner, I956). As Berger (1963) notes: "the fascination of sociology lies in the fact that its perspective makes us see in a new light the very world in which we have lived all our lives. This also constitutes a transformation of consciousness" (Berger, I963: 2I). I found this to be another enriching aspect of the experience of stepping out of my familiar routine and becoming the person "on the margins" (Macionis \& Plummer, 2005: p. 8). 


\section{References}

Anderson, L. (2006). Analytic autoethnography. Journal of contemporary ethnography, 35(4), 373-395.

Angrosino, M. (2007). Doing ethnographic and observational research. Sage.

Atkinson, P. (2006). Rescuing autoethnography. Journal of contemporary ethnography, 35(4), 400-404.

Berger, P. L. (1963). Invitation to sociology. A humanistic perspective: Garden City, NY: Doubleday.

Boyd, D. (2008). Autoethnography as a tool for transformative learning about white privilege. Journal of Transformative Education, 6(3), 212-225.

Corbin, J., \& Strauss, A. (2008). Basics of qualitative research: Techniques and procedures for developing grounded theory. Sage.

Crawford, L., \& Novak, K. (2013). Individual and society: sociological social psychology. Routledge.

Dexter, S., \& LaMagdeleine, D. R. (2002). Dominance theater, slam-a-thon, and cargo cults. Three illustrations of how using conceptual metaphors in qualitative research works. Qualitative Inquiry, 8(3), 362 380.

Ellis, C., Adams, T. E., \& Bochner, A. P. (2010). Autoethnography: An Overview. 2010, I2(I).

Feder-Alford, E. (2006). Only a Piece of Meat One Patient's Reflections on Her Eight-Day Hospital Experience. Qualitative Inquiry, I2(3), 596-620.

Flick, U. (2008). Managing quality in qualitative research. Thousand Oaks: SAGE publications.

Gibbon, J. (2012). Understandings of accountability: an autoethnographic account using metaphor. Critical Perspectives on Accounting, 23(3), 20I-2I2.

Gie, J. (2009). Crime in Cape Town: 2001-2008: A brief analysis of reported violent, property and drugrelated crime in Cape Town: City of Cape Town.

Gilson, L., Elloker, S., Olckers, P., \& Lehmann, U. (2014). Advancing the application of systems thinking in health: South African examples of a leadership of sensemaking for primary health care. Health Res Policy Syst, I2(30), I0.II86.

Glenn, P. (2010). Interviewer laughs: Shared laughter and asymmetries in employment interviews. Journal of Pragmatics, 42(6), I485-I498.

Goffman, E. (1956). The presentation of self in everyday life.

Griffin, E. (2006). Communication: A first look at communication theory. Boston: McGraw-Hill.

Houssay-Holzschuch, M., \& Teppo, A. (2009). A mall for all? Race and public space in post-apartheid Cape Town. cultural geographies, I6(3), 351-379.

Jacobsen, M. H., \& Kristiansen, S. (2014). The Social Thought of Erving Goffman. SAGE Publications.

Jubas, K., \& Seidel, J. (20I4). Knitting as Metaphor for Work An Institutional Autoethnography to Surface Tensions of Visibility and Invisibility in the Neoliberal Academy. Journal of contemporary ethnography, 089124I614550200.

Kay, D. (2004). South African City Planning in a Post Apartheid Era.

Kivisto, P., \& Pittman, D. (1998). Goffman's Dramaturgical Sociology: Personal sales and service in a commodified world. IN: Kivisto P (ed) Illuminating Social Life: California: Pine Forge Press.

Larkan, F. (20II). Writing Henry: The moralities of representation. Irish Journal of Anthropology, I4(I), 43-49.

Lewis-Beck, M., Bryman, A. E., \& Liao, T. F. (2003). The Sage encyclopedia of social science research methods. Sage Publications.

Lundgaard Andersen, L. (2012). Interaction, transference, and subjectivity: A psychoanalytic approach to fieldwork. Journal of Research Practice.

Macionis, J. J., \& Plummer, K. (2005). Sociology: A Global Introduction. (third ed.): Pearson Education.

Mahlangeni, B. M. (2013). Reflections on the impact of the natives' land act, 1913, on local governement in South Africa. Retrieved from 
Masquillier, C., Wouters, E., Mortelmans, D., \& le Roux Booysen, F. (2015). The Impact of Community Support Initiatives on the Stigma Experienced by People Living with HIV|AIDS in South Africa. AIDS and Behavior, I9(2), 2I4-226.

Masquillier, C., Wouters, E., Mortelmans, D., \& van Wyk, B. (2015). On the Road to HIV|AIDS Competence in the Household: Building a Health-Enabling Environment for People Living with HIV|AIDS. International Journal of Environmental Research and Public Health, I2(3), 3264-3292.

Masquillier, C., Wouters, E., Mortelmans, D., Van Wyk, B., Hausler, H., \& Van Damme, W. (20I6). HIV/ AIDS Competent Households: Interaction between a Health-enabling Environment and Community-Based Treatment Adherence Support for People Living with HIV/AIDS in South Africa. PLoS One, II(3), I-I9.

Masquillier, C., Wouters, E., Mortelmans, D., Van Wyk, B., \& Van Damme, W. (In review). The Role of HIV| AIDS Competent Households in Providing Community-Based Treatment Adherence Support for People Living with HIV|AIDS in South Africa. PLoS One.

Miner, H. (1956). Body ritual among the Nacirema. American Anthropologist, 503-507.

Mortelmans, D. (2013). Handboek Kwalitatieve onderzoeksmethoden.

Nhamo, M., Campbell, C., \& Gregson, S. (2010). Obstacles to local-level AIDS competence in rural Zimbabwe: putting HIV prevention in context. Aids Care, 22(S2), I662-I669.

Norrick, N. R. (2009). A theory of humor in interaction. Journal of Literary Theory, 3(2), 26I-283.

Odendaal, W. A., \& Lewin, S. (2014). The provision of TB and HIV/AIDS treatment support by lay health workers in South Africa: a time-and-motion study. Human Resources for Health, I2(I), I-7. doi:Io.II86/I478$449 \mathrm{I}-\mathrm{I} 2-\mathrm{I} 8$

Otter, S. (2007). Khayelitsha: uMlungu in a Township.

Posel, D. (200I). What's in a name? Racial categorisations under apartheid and their afterlife. TRANSFORMATION-DURBAN-, 50-74.

Radley, A., \& Billig, M. (1996). Accounts of health and illness: Dilemmas and representations. Sociology of Health \& Illness, I8(2), 220-240.

Rafalovich, A. (2006). Making sociology relevant: the assignment and application of breaching experiments. Teaching Sociology, $156-163$.

Raffel, S. (2013). The everyday life of the self: Reworking early Goffman. Journal of Classical Sociology, I3(I), I63-178.

Schuermans, N. (20II). Anxieties, identities and spatialities: ambivalent geographies of encounter in Cape Town and Flanders. (PhD), KUL, Leuven.

Schulz, H. M. (2012). Exploring dramaturgy in consumer research. Journal of Research for Consumers, 2I(I), I-I9.

Seekings, J. (2008). The continuing salience of race: Discrimination and diversity in South Africa. Journal of contemporary African studies, 26(I), I-25.

Simmel, G. (1950). The stranger. The Sociology of Georg Simmel, 402-408.

Tong, A., Sainsbury, P., \& Craig, J. (2007). Consolidated criteria for reporting qualitative research (COREQ): a 32-item checklist for interviews and focus groups. International Journal for Quality in Health Care, I9(6), 349-357.

Tracy, S. J. (2010). Qualitative quality: Eight "big-tent" criteria for excellent qualitative research. Qualitative Inquiry, r6(ro), 837-851.

Treviño, J. A. (2003). Goffman's legacy. Rowman \& Littlefield Publishers.

Turok, I. (200I). Persistent polarisation post-apartheid? Progress towards urban integration in Cape Town. Urban studies, 38(13), 2349-2377.

Wouters, E., Masquillier, C., Ponnet, K., \& Booysen, F. (2014). A peer adherence support intervention to improve the antiretroviral treatment outcomes of HIV patients in South Africa: The moderating role of family dynamics. Social Science \& Medicine. doi:http://dx.doi.org/ro.ror6/j.socscimed.2014.05.020 